\title{
Hyperthermia is a predictor of high mortality in patients with sepsis
}

\author{
Yanfei Shen ${ }^{1}$, Yangfang $\mathrm{Lou}^{2}$ and Shiping Zhu ${ }^{2^{*}}$ (D)
}

To the Editor,

In a recent study, Shimazui et al. [1] reported that body temperature (BT) on ICU admission exhibited different predictive values in elderly and non-elderly patients with sepsis, and only hypothermia $\left(\mathrm{BT}<36.0^{\circ} \mathrm{C}\right)$ was associated with increased mortality in non-elderly patients while hyperthermia $\left(\mathrm{BT}>38.3^{\circ} \mathrm{C}\right)$ was not. A few issues should be noted.

First, the grouping method may underestimate the impact of hyperthermia. In the current study, the whole cohort was divided into the hyperthermia and nonhyperthermia groups, using a cutoff value of BT at $38.3^{\circ} \mathrm{C}$. One limitation is that under this grouping method, both hypothermia and normothermia were classified as non-hyperthermia. Thus, the comparison between the hyperthermia and non-hyperthermia groups could be susceptible to the proportion of patients with hypothermia. For instance, in two hypothetical cohorts (cohort 1: hypothermia $n=80$, normothermia $n=20$, hyperthermia $n=100$ vs. cohort 2: hypothermia $n=20$, normothermia $n=80$, hyperthermia $n=100$ ), the comparison of mortality between the hyperthermia and non- hyperthermia groups could be quite different in these two cohorts, as the non-hyperthermia group in cohort 1 (high proportion of hypothermia patients) may have high mortality. In addition, several studies [2] also reported that in sepsis, hyperthermia $\left(\mathrm{T}_{\max }\right)$ was also a significant risk for high mortality. Furthermore, one randomized controlled trial (RCT) found that fever control using external cooling to maintain BT between 36.5 and $37.0^{\circ} \mathrm{C}$ significantly reduced mortality in septic shock [3]. For validation, we explored the association between $\mathrm{BT}$ and mortality in another cohort from MIMIC-III database (Fig. 1). A total of 4201 adult patients with sepsis were included. Consistent with the current study, different associations between BT and mortality were also found in old $(\geq 75)$ and young $(<75)$ patients. However, in patients with age $<75$, both hypothermia and hyperthermia exhibited increased trends of in-hospital mortality (Fig. 1 black bars).

Second, the author mentioned that the impact of hypothermia duration on mortality remained unclear. Noteworthy, in a median analysis of previous RCT [3], Schortgen et al. [4] found that $73 \%$ of the impact of

\footnotetext{
* Correspondence: zsping0908@163.com

2Department of Respiratory Medicine, Hangzhou Hospital of Traditional

Chinese Medicine, No. 453, Tiyuchang Road, Hangzhou 310000, Zhejiang,

China

Full list of author information is available at the end of the article
} licence and your intended use is not permitted by statutory regulation or exceeds the permitted use, you will need to obtain permission directly from the copyright holder. To view a copy of this licence, visit http://creativecommons.org/licenses/by/4.0/. The Creative Commons Public Domain Dedication waiver (http://creativecommons.org/publicdomain/zero/1.0/) applies to the data made available in this article, unless otherwise stated in a credit line to the data. 


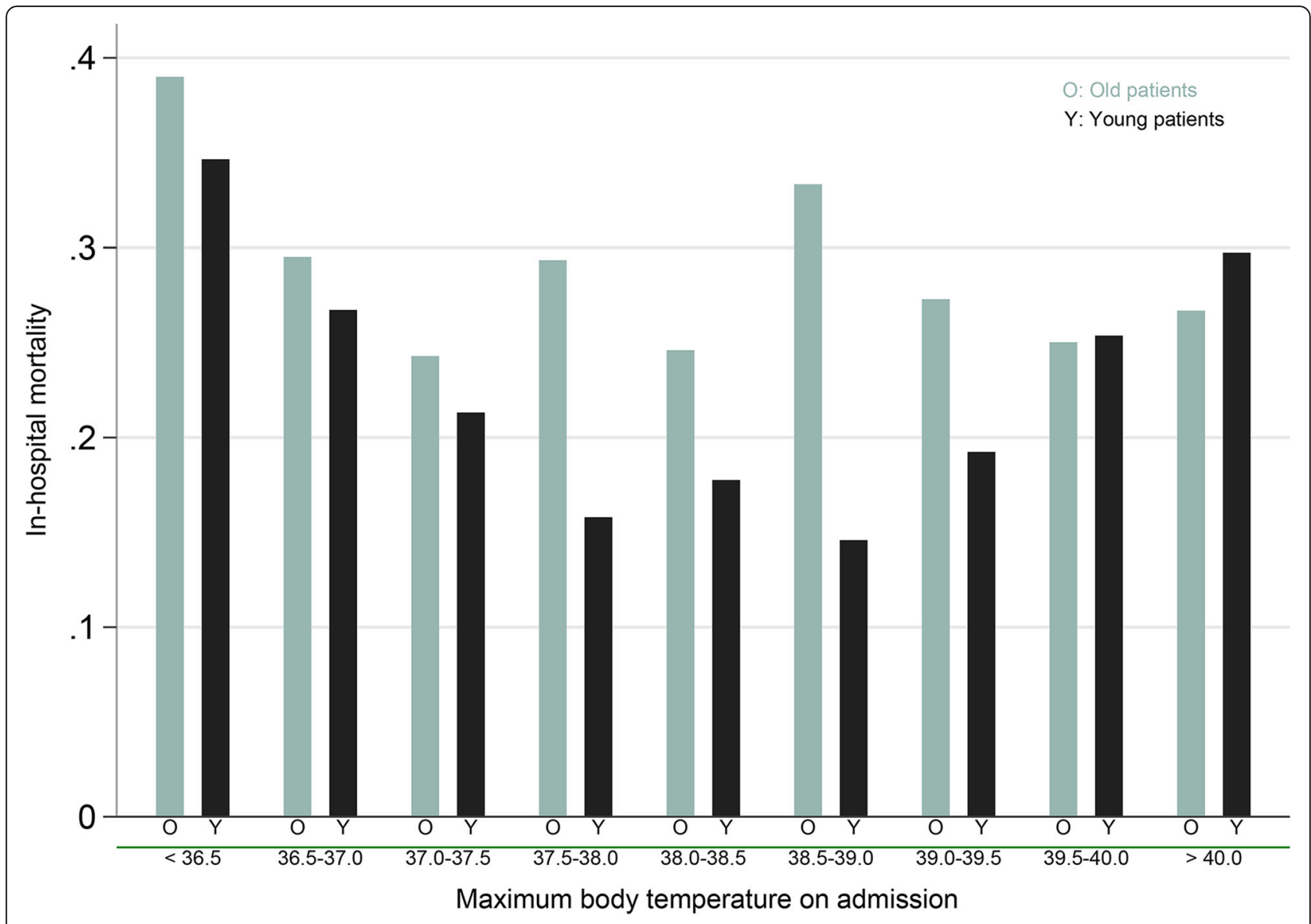

Fig. 1 Association between body temperature and in-hospital mortality in old ( $\geq 75$ years old) and young ( $<75$ years old) patients with sepsis

external cooling on mortality was mediated by the duration of $\mathrm{BT}<38.4{ }^{\circ} \mathrm{C}$. Thus, focusing on a single $\mathrm{BT}$ record may increase the bias risk. Temperature load (TL) [5] may be a method to this limitation, defined as the sum of BT above/below the targeted temperature level multiplied by the duration (hours). For instance, the TL of hyperthermia $\left(>38.3^{\circ} \mathrm{C}\right)$ within $72 \mathrm{~h}$ should be calculated as follows-step 1: $\overline{t_{i}}=\frac{t_{i}+\mathrm{t}_{\mathrm{i}+1}}{2}-38.3$; step 2: $\mathrm{TL}=\sum_{i=1}^{72} \overline{t_{i}} \times 1$ hour.

\section{Acknowledgements}

Not applicable.

\section{Authors' contributions}

S.Z. and W.C. came up with the question, and S.Z. was responsible for the writing. The authors read and approved the final manuscript.

\section{Funding}

YS received funding from the Zhejiang medical and health science and technology project (no. 2018261355).

Availability of data and materials Not applicable.
Ethics approval and consent to participate Not applicable.

\section{Consent for publication}

Not applicable.

\section{Competing interests}

None.

\section{Author details}

${ }^{1}$ Department of Intensive Care, Zhejiang Hospital, 1220\#, Gudun-Road, Hangzhou, Zhejiang, China. ${ }^{2}$ Department of Respiratory Medicine, Hangzhou Hospital of Traditional Chinese Medicine, No. 453, Tiyuchang Road, Hangzhou 310000, Zhejiang, China.

Received: 18 August 2020 Accepted: 24 August 2020 Published online: 03 September 2020

\section{References}

1. Shimazui T, Nakada TA, Walley KR, Oshima T, Abe T, Ogura H, Shiraishi A, Kushimoto S, Saitoh D, Fujishima S, et al. Significance of body temperature in elderly patients with sepsis. Crit Care. 2020;24(1):387.

2. Wu DY, Lu SQ. The effects of abnormal body temperature on the prognosis of patients with septic shock. Ther Hypothermia Temp Manag. 2019. Epub ahead of print. PMID: 31895653. https://doi.org/10.1089/ther.2019.0012.

3. Schortgen F, Clabault K, Katsahian S, Devaquet J, Mercat A, Deye N, Dellamonica J, Bouadma L, Cook F, Beji O, et al. Fever control using external 
cooling in septic shock: a randomized controlled trial. Am J Respir Crit Care Med. 2012;185(10):1088-95.

4. Schortgen F, Charles-Nelson A, Bouadma L, Bizouard G, Brochard L, Katsahian $\mathrm{S}$. Respective impact of lowering body temperature and heart rate on mortality in septic shock: mediation analysis of a randomized trial. Intensive Care Med. 2015;41(10):1800-8.

5. Rahmig J, Kuhn M, Neugebauer $H$, Juttler E, Reichmann $H$, Schneider $H$. Normothermia after decompressive surgery for space-occupying middle cerebral artery infarction: a protocol-based approach. BMC Neurol. 2017; 17(1):205.

\section{Publisher's Note}

Springer Nature remains neutral with regard to jurisdictional claims in published maps and institutional affiliations. 